\title{
UNA NUEVA LECTURA DE RAZÓN DE AMOR
}

a mis padres

Razón de Amor es un poema de difícil explicación. Es un poema medieval de autor desconocido que se nos da a conocer por primera vez en 1887 por Morel-Fatio. Desde esa fecha, se han escrito diversos artículos de todo tipo, intentando encontrar o descubrir su sentido último, su estructura, su unidad, etc. La mayoría de la crítica ha fijado su interés en intentar encontrar su unidad compositiva o en negársela. No es extraño que esto haya sido así porque, no es normal encontrarnos dos composiciones tan distintas, como lo son un poema de amor $\mathrm{y}$ un debate goliardesco, en una sola obra.

Como sabemos, en la Edad Media con frecuencia se ha tratado el problema de las relaciones entre el amor y el sexo. El amor debía ser espiritual y el sexo y la carne eran aspectos mortalmente pecaminosos. Sin embargo, había quien no pensaba lo mismo. Eso es lo que podemos ver tras la interpretación que haremos de Razón de Amor; también se podría obșervar lo mismo con el Libro de Buen Amor del Arcipreste de Hita. Juan Ruiz, con su característico vitalismo, llega a la conclusión de que los hombres son carne y espíritu; deberíamos poder gozar de los "dos amores". Esa discusión se plantea y resuelve también, en el poema que nos ocupa. Este poema, dentro de su aparente simplicidad, encierra un pensamiento muy moderno para su época; o, cuando menos, bastante innovador.

En este trabajo intentaremos demostrar que dos fenómenos que en un principio pueden parecer muy distantes entre sí, e incluso contradictorios, no lo están tanto, si penetramos en sus significados y connotaciones más profundas.

Cuando leemos el poema por primera vez, lo hacemos de un tirón, aunque nos damos cuenta de que hay un cambio de estilo, una ruptura, hacia la mitad. Empezamos a leer y nos encontramos con un poema de amor que transcurre plácidamente, con la descripción de un verdadero "locus amoenus", en el que un hombre y una mujer se unen y posteriormente se separan. Seguidamente, aparece una paloma que vierte el contenido de una copa llena de agua en una que tiene vino - copas que han sido descritas con anterioridad-. Así comienza un debate típicamente galiardesco entre el vino y el agua; ahora la lectura se acelera con el diálogo; ya no son palabras dulces de enamorados, sino un juego dialéctico de insultos, una lucha verbal por ver quién es mejor o peor de los dos.

La paloma y su accidentado vuelo se convierten en el elemento clave del poema, que enlaza, sin aparente quiebra, ambas partes. Salta a la vista, no obstante, que se rompe con la estructura argumental, con el tipo y con la atmósfera de la composición, pero no con el sentido del poema, el que nosotros vamos, precisamente, a proponer. 
En cuanto a la estructura, hay quien piensa, como Daniel $\mathrm{K}$. Cárdenas, a causa de los aragonesismos que se encuentran en la segunda parte y no en la primera, que son dos poemas unidos por un inteligente copista, ${ }^{1}$ este habría antepuesto una introducción al poema de amor y a continuación habría añadido el debate de corte goliardesco.

Es una teoría lógica y razonable, puesto que nos permite concluir que el poema que nos ha llegado es uno y sólo uno, unido compositiva y temáticamente desde el momento en que el copista así lo quiso. Quizá, como argumenta María Cristina Azuela, ${ }^{2}$ la unidad compositiva la den todos esos contrastes y paralelismos que encontramos a lo largo de toda la obra. Es un constante enfrentamiento que se resuelve con la unión final de los contrarios, tal como pensaba Spitzer; ${ }^{3}$ pero $i$ son tan contrarios?

En el campo interpretativo también hay diversidad de opiniones. Jacob ${ }^{4}$ ve símbolos religiosos por todo el poema; desde el agua hasta la paloma, y la muchacha como una alegoría de la Virgen. Esto último, sobre todo, es muy dudoso porque, al leer la composición, vemos como ella se acuesta con el joven y eso no conviene con la idea que de la Virgen poseemos. Se pueden encontrar símbolos religiosos pero, desde luego, este poema no es, desde nuestro punto de vista, de tema religioso ni mucho menos. Spitzer ${ }^{5}$ daba a la sed el papel primordial; a ella le atribuía la función de incitadora para llegar a los dos amores. También hay quien ha intentado relacionar a la mujer con el agua — símbolos de pureza- y al hombre con el vino - la lujuria-. Esta relación podría darse, pero de otro modo; quizá después de estas líneas adivinemos de qué manera.

Para demostrar que en el poema se llega al perfecto equilibrio entre las dos vías, la espiritual y la carnal, se analizarán el texto y las connotaciones que se derivan de cada uno de los protagonistas. Para comprobar que no todo es blanco o negro, lo que hay que hacer es buscar los tonos grises del texto; es decir, encontrar actitudes sensuales, vale decir vitales, y castas en cada uno de los personajes: la mujer, el hombre, el agua y el vino.

La primera gran oposición que encontramos es de carácter textual; un poema de amor y un debate goliardesco. Se oponen pero, como se dijo al principio, se puede leer y concebir como un todo continuo y esto no se nos hace demasiado extraño. Este hecho y el que, tanto al principio como al final, quien habla sea el mismo Juglar que nos cuenta la historia dotan de unidad al poema. El logro del autor o del inteligente copista resulta así excelente y eficaz; aunque diferenciamos los dos poemas, nos es imposible dar un tijeretazo y dividirlos. Esta unión estructural ¿no tendrá algo que ver con el contenido? Probablemente sí que se pueda relacionar con la disputa antes mencionada.

\footnotetext{
1 Daniel N. Cárdenas: Nueva luz sobre la Razón de Amor, Crítica, Barcelona, 1980.

2 María Cristina Azuela: "La ambigüedad en la Razón de Amor", NRFH, XLI (1993), núm. 1, pp. $201-214$.

${ }^{3}$ Leo Spitzer: Razón de Amor, Romania, 71, 1950.

${ }^{4}$ Alfred Jacob: "The Razón de Amor as Christian symbolism", Hispanic Review, XX, 1952.

5 Ibid. pág. 3.
} 
En la muchacha y en el hombre, se pueden encontrar fácilmente actitudes tanto espirituales como marcadamente sensuales o vitales. La mujer llega cantando de amor y, en los versos $80-81$, nos dice 6 :

$$
\begin{aligned}
& \text {...Amet sempre, e amare } \\
& \text { quanto que uiua sere... }
\end{aligned}
$$

Y continúa con su canto:

$$
\begin{aligned}
& \text {... Mas amaria contigo estar } \\
& \text { que toda Espana mandar... }
\end{aligned}
$$

Después comenta que tiene miedo porque dicen que hay otra mujer que también le quiere. Y reacciona en los versos $96-97$ de este modo:

$$
\begin{aligned}
& \text {... Mas s' io te uies una uegada, } \\
& \text { a plan me queryes por amada... }
\end{aligned}
$$

Tales declaraciones no nos extrañan, pero, cuando pasamos más adelante, comprobamos que ella, en el verso 109 , le declara al joven:

...mas non connozco mi amado...

Ella ama sin ver, sin conocer; es un amor platónico - a distancia - Está enamorada por las descripciones y regalos que el mensajero le ha dado. Podríamos incluso ir más lejos en la interpretación; podríamos pensar, por las connotaciones bíblicas del verbo usado, que la muchacha no ha mantenido nunca relaciones sexuales con el joven. Con ello tendriamos una inesperada faceta espiritual y casta de la mujer.

Antes de pasar a determinar sus facetas más sensuales y vitales, he aquí, las palabras con que se despide del amado:

... bien seguro seyt de mi amor,

no uos camiare por un umperador...

A pesar de todo, sin embargo, cuando -en los versos 124-125 - se da cuenta de que el hombre con el que estaba hablando tranquilamente es de quien está enamorada,

$$
\begin{aligned}
& \text {... Toliose el manto de los ombros } \\
& \text { besome la boca e por los oios; } \\
& \text { tan gran sabor de mi auia, } \\
& \text { sol fablar non me podia... }
\end{aligned}
$$

\footnotetext{
${ }^{6}$ De la edición de J. J. de Bustos Tovar: Razón de Amor con los denuestos del agua y del vino, El Comentario de Textos, IV. La poesía medieval, Castalia, Madrid, 1994.
} 
Como vemos, aparte del amor espiritual, ella se rinde y desea también un amor manifiestamente fisico, plenamente carnal. En ella conviven lo sensual y lo castamente espiritual y desinteresado, como hemos visto en la despedida.

El caso del personaje del hombre es muy parecido al del que representa la doncella; él también está enamorado sin conocer a su amada. Empieza a darse cuenta de que él es el amado, por lo que ella dice en los versos 110 a 115 :

... pero dizem un su mesaiero

que es clerygo e non caualero, sabe muito de trobar, de leyer e de cantar; dizem que es de buenas yentes, mancebo para barua punnientes...

Él lo comprueba preguntándole:

...Por Dios, que digades, la mia senor, que donas tenedes por la su amor?... (vv. 116-117)

Cuando ella le contesta, se reconocen mutuamente y se unen en la pasión que hemos visto más arriba.

Después de una grant pieça alli estando, de nuestro amor enmentando, se despiden, como sabemos, pero él también desea seguir amando y ser fielmente amado:

...yt, la mia senor, pues que yr queredes,

mas de mi amor pensat, fe que deuedes... (vv. 138-139)

Se queda triste y solo:

... La mia senor se ua priuado,

deja a mi desconortado.

Que la ui fuera del uerto

por poco non fuy muerto. (vv. 142-145)

Podemos ver, entonces, que en el hombre también conviven las dos actitudes, la espiritual y la sensual.

La acción argumental, a partir de ahora, con el debate, dará un inesperado giro: es la misma paloma que el caballero ve posarse, la que, después de refrescarse, vierte el agua sobre el vino y comienza la denostación con la intervención de este quejándose de su inesperada compañera.

Por el diálogo y prestando atención a las diversas cualidades que cada uno de los contrincantes atribuye al otro, encontraremos las dos facetas también en estos nuevos personajes.

Del agua, lo primero que sabemos es que está fría, y que el joven no se atreve a beberla por miedo a que esté encantada. En lo que atañe al vino, se refiere a ella despreciándola: 
... Agua, as mala mana, ...

non queria auer la tu conpana;

que cuando te legas a buen tino

fazeslo feble e mesquino... (vv. 165-169)

... antes amaryella e astrosa,

agora uermeia e fermosa... (vv. 189 y 190)

Para terminar anticipando su fatal transformación en barro:

... sueles lauar pies e manos

e limpiar lixos panos,

e sueles tanto andar con poluo mesclada

fasta que en el lodo eres tornada...(vv. 238-241)

Sin embargo, el agua es también símbolo de pureza, de castidad, del bautismo purificador - que de agua fazen el bautísm (vv. 255-259)-, y se presenta clara y fresca para el muchacho:

...Pleguem a una fuente perenal...

...tan grant uirtut en si auia,

que de la frydor de d'y yxia, ...

...non sintyades la calor... (vv. 37-42)

El agua refresca del calor $y$, por lo que se dice en los versos siguientes, da vida a todo tipo de bellas flores.

El muchacho bebe de ese agua y se refresca; el agua le reconforta el cuerpo sediento y acalorado. Es más, cuando se ha refrescado, exclama: en mi mano pris una flor e quis cantar de fino amor. Quiere cantar de fino amor, no de ningún otro. El ambiente que crea el frescor del agua de la fuente con sus aromáticas flores y el fresco trago hacen que el joven se sienta exaltado y quiera cantar de fino amor.

Además, es fuente de la vida: en los versos 197 a 204, el agua responde al vino que es hijo de la cepa y si no fuera por el agua que llueve, a su madre hacía tiempo que la habrían cortado.

El agua, símbolo de pureza y castidad, también puede ser elemento sensual, e inductora de refinado placer.

El vino siempre ha sido considerado como el símbolo de la embriaguez, de lo impuro, de la lujuria, etc. El agua, para defenderse, recalca todas esas cualidades. Por ejemplo, en los versos 178 a 182, nos recuerda los efectos que causa el vino:

...los buenos uos precian poco,

que del sabio fazes loco,

no es homne tan senado 
que de ti sea fartado,

que non haya perdido el sesso y el Recabdo...

Un poco más adelante será el propio vino el que se jacte de ello:

...e io derribo a muchos valientes;

e si farya a quantos en el mundo son,

e si uiuo fuese, Sanson. (vv. 211-213)

El agua, con los ejemplos que pone, hace hincapié en lo malo del vino y deja muy claras sus lúbricas connotaciones. Sin embargo, si leemos con un poco de atención, descubriremos que el vino también tiene otras propiedades bien distintas. Ya en la primera parte del poema las encontramos; cuando el joven describe el paisaje y ve las copas, comenta de la del vino:

...un uaso de plata ui estar;

pleno era d'un claro uino

que era uermeio e fino... (vv. 14-16)

Y más adelante

...Qui de tal uino oviesse

en la mana quan comiesse:

e dello ouiesse cada dia

nunca mas enfermarya... (vv. 23-26)

¿Qué puede tener de malo un fluido que si lo bebes, no enfermas nunca?

... yo fago al ciego veyer

y al coxo correr

y al mudo faublar y al enfermo organar;

asi como dize en el scripto,

de mi fazen el cuerpo de Iesu Chrísto... (vv. 246-251)

El vino hace correr al cojo, al ciego le hace ver, hace hablar al mudo, al enfermo, sanar; tópicos sobre los efectos del alcohol, pero, además, el vino es la materia de la que se hace el cuerpo de Cristo; esto ya es más serio.

¿No serán, pues, aquellos, considerados de esta manera, la relación de los efectos milagrosos de su naturaleza divina? Probablemente, sí. Estas cualidades nos darían el aspecto más espiritual y purificador del vino.

Comprobamos, así, que el vino, aparte de ser el símbolo de la embriaguez y del exceso, puede tener también otras connotaciones diferentes, que esta lectura del poema nos muestra.

Hemos visto como el hombre y la mujer tienen los dos aspectos, el espiritual y el carnal; que se desean y se aman delicadamente, que consuman su deseo y, aun así, no renuncian a los placeres espirituales que provoca el sentimiento. 
Del mismo modo, nos hemos dado cuenta de que en el vino, como en el agua, podemos encontrar elementos puros e impuros; espirituales, incluso religiosos, y terrenales.

Ahora sí podríamos relacionar a la mujer con el agua y al vino con el hombre; pero no podríamos identificar el agua y la mujer con la pureza y el hombre y el vino con todo lo contrario.

Al igual que el agua cae sobre el vino, la muchacha llega al hombre. El que primero habla, una vez en contacto, son el hombre y el vino. Y, por último, en la despedida, es la mujer la última en hablar, como también lo es el agua después. La distribución estructural y simbólica parece ser simétrica no porque se enfrenten dos parejas de contrarios. No son exactamente contrarios, son elementos distintos que pueden compartir propiedades semejantes y que, al fin y al cabo, pueden convivir perfectamente.

Analizando el poema en su conjunto, hallamos finales semejantes. El hombre y la mujer consuman su amor y se despiden, pero quedan ligados por ese amor que se han prometido en la despedida.

De forma similar, el agua y el vino terminan el diálogo y quedan mezclados irremediablemente. El autor no le da la razón a una o a otro; les deja sin más unidos indisolublemente.

De la misma manera que el amor espiritual y el amor físico, en la primera parte, se compaginan sin considerarse uno superior al otro, sino más bien complementarios; en la segunda parte, asistimos a la mezcla final e indisoluble de elementos tan distintos, en un principio, como el agua y el vino. Esto mostraría por sí mismo que para el autor o para el escriba, cualquiera que nos haya transmitido la versión única que poseemos del poema final, la mezcla de lo puro y de lo impuro, de lo casto y de lo lujurioso es posible.

Un poema tan sencillo, a primera vista, puede encerrar una filosofía y una forma de ver la vida que nos sorprende. Una filosofía vitalista que quizá, por la mezcla de culturas en que se da, conlleve influjos de sensualidades diversas; algo que el espiritualismo medieval cristiano no aceptaba. Un poema que, desde su misma estructura, intenta, y consigue, integrar dos géneros muy distintos.

Podríamos interpretar ese afán de unir dos composiciones tan diferentes como el escondido deseo de demostrar la complementariedad de los contrarios, por una parte, de lo espiritual y de lo sensual, y, por otra parte, de los mundos literarios e ideológicos que representarían esos dos tipos de composiciones, uno imbuido de un fuerte contenido platónico y contemplativo y otro que propende a la diversión y al disfrute del mundo. 


\section{DRUGAČNO BRANJE RAZÓN DE AMOR}

Razón de Amor je srednjeveška anonimna pesem, razdeljena na dva dela: ljubezensko pesem, kjer sta protagonista ženska in moški, in na dialog med vodo in vinom.

Avtor prispevka $\mathrm{z}$ analizo pesmi ugotavlja, da je pred nami še en primer za srednji vek inovativne stvaritve, saj se pesnik zavzema tako za duhovno kot telesno, meseno ljubezen, ki sta eno, kot nam to sporoča tudi Libro de Buen Amor. Prav tako ponazarja, da oba dela pesmi nista zgolj opoziciji, kot tudi ne na videz nasprotna si para ženska in moški ter voda in vino. Vsi elementi so povezani, komplementarni, $\mathrm{v}$ svoji različnosti nosijo podobne elemente, ki omogočajo sobivanje. Gre za percepcijo sveta, ki ne išče le črnega in belega, pač pa želi pokazati komplementarnost nasprotnih si elementov in njihovo bogastvo. 